\title{
Time to resuscitate cardiopulmonary resuscitation! The 3R/CPR: Refill-Recoil-Rebound.
}

Sayed NOUR MD, PhD ${ }^{\bowtie}$

Le LAB'O, Orleans Technopole, 1 avenue du Champs de Mars - 45074 Orleans France.

Short Title: Shear stress therapy in Covid-19.

$\bowtie$ Corresponding author: Dr. Sayed Nournourmd@mac.com

IID: https://orcid.org/0000-0002-3853-0942 


\begin{abstract}
Sudden cardiac arrest (SCA) remains a major health issue worldwide with a gloomy outcome due to the inadequate organs' perfusion during cardiopulmonary resuscitation (CPR). Alternatively, we aim through the present work to expose our visions of SCA management and propose a new technique of cardiac massage, urging CPR experts around the world to conduct their in-depth reviews for the sake of patients.
\end{abstract}

Keywords: Sudden cardiac arrest, Cardiopulmonary resuscitation (CPR), Circulatory flow resuscitation, 3R/CPR. 


\section{Introduction}

"Science is nothing but trained and organized common sense" Thomas Huxley ${ }^{[1]}$

Clinically, sudden cardiac arrest (SCA) can be identified by the abrupt discontinuity of organs' perfusion due to sudden ventricular asystole, whether fibrillated or knocked-out [2,3], provoked by physiopathological events [4-6]; pathophysiological cardiac-extracardiac disorders [7-9]; or intentionally induced, In-hospitals (IHCA) or Out-of-hospitals (OHCA).

Most commonly, incidences of OHCA occur unwitnessed due to cardiac arrhythmia, distinct from heart attacks which are usually preceded by symptoms and signs [10-12]. Despite imprecise statistics, more than 1,250,000 OHCAs occur each year in North America and Europe [(13,14].

Current management of cardiac arrest or cardiopulmonary resuscitation (CPR) is generally performed by cardiac massage, whether manually with repeated chest compressions, interrupted by mouth-to-mouth ventilation at rates of 30: 2 ; or mechanically with devices to compensate for rescuers' fatigue [15,16]. Direct-Current (DC) Cardioversion-Defibrillation [17], is an essential procedure for cardiac arrest management, usually delivered with an automated external defibrillator (AED) [18] or with implantable cardioverter defibrillators (ICD) in congestive heart failure patients with high risks of fatal arrhythmias [19]. Epinephrine, hypothermia, E-CPR with the employment of extracorporeal membrane oxygenation (ECMO) are also taken into account for the management of SCA [20-22]. The cardiopulmonary bypass (CPB) with open-chest direct cardiac massage can be considered under special circumstances [23]. The postresuscitation care for CPR survivors includes a hemodynamic support, control of blood biochemistry and avoiding a routine hyperventilation [24].

Despite scientific progress and supports of Global Health Systems, the outcome of SCA victims still remains quite poor due to the inadequate perfusion of vital organs during CPR [25, 26]. As a result, more than half of postresuscitation syndrome deaths occur within $24 \mathrm{~h}$ after the return of spontaneous circulation (ROSC), due to multiple organs failure and about $2 \%$ of the victims may survive without brain damage the first year postarrest [27-29]. This makes CPR one of the most controversial therapeutic concept in modern medical history, which requires a fundamental scientific overhaul.

Previously, we have demonstrated the benefits of prioritizing immediate restoration of circulatory flow dynamics over exhorting return of heartbeat, using a low-pressure extracorporeal pulsatile device, (CFR vs. CPR) [30]. A noninvasive device adapted to the cardiopulmonary-circulatory pathophysiology and biophysics that can maintain endothelial shear stress (ESS), organs' perfusion, and predispose to ROSC in reasonable metabolic and hemodynamic conditions, applicable in refractory cardiac arrest [31], as well as in postarrest. 
The goal of this study is to propose a new technique of cardiac massage adaptable to cardiovascular pathophysiology, biophysics and the overlooked thoracic biomechanics, to be used in the early onsets of cardiac arrest. A safer and more effective method, which can be used by a bystander and/ or a rescuer in less exhaustive efforts, outside and/or inside hospital environment, promoting potential improvements of current CPR outcome.

We boosted our study by analyzing clinical observations of the three components of the CPR framework, namely victims, methods, and therapists, particularly those of lifeguards and heart surgeons.

\section{Methods}

\section{Therapeutic approach}

Although victims of SCA are quite diverse, e.g., gender, age, etiology, ..., however, they all share the same trilogy of therapeutic barriers, which must be overcome during CPR, namely the cardiac electrophysiology, the hemostatic-hemorheological condition and the cardiothoracic anatomy.

As it is known, a heartbeat starts from within the heart by the action potential at the conducting system inside the right atrium (RA) wall, septum, .... In other words, blood flow dynamics control heartbeats, biochemically, with the combinations of neurohumoral factors that create polarizationdepolarization activities at the pacemaker cells of the conducting system, and mechanically, via the pulsatile impacts of shear stress and wall stress, since the $21^{\text {st }}$ day of gestation [32]. The superiority of blood flow dynamics in controlling heartbeat over the autonomic nervous system is demonstrated with the denervated hearts transplant patients [33]. Likewise, disturbed RA wall stress can induce variant types of arrhythmias, e.g., post Mustard arrhythmias [34].

Following the hemostatic state, within 30 seconds of cardiac arrest, the left-heart side which normally contains $\leq 10 \%$ of blood volume (BV) becomes almost empty with an aortic pressure (AP) $=0 \mathrm{~mm} \mathrm{Hg}$. Similarly, the adult heart which roughly contains $\leq 400 \mathrm{~mL}$ of BV, unequally divided between its chambers, becomes nearly empty as part of the intracardiac blood moves backwardforward through the low-pressure valveless vena cavae and the pulmonary artery. Consequently, the stagnant venous capacitance increases, and the venous pressure rises from $\leq 0 \mathrm{~mm} \mathrm{Hg}$ to $\geq 20$ $\mathrm{mm} \mathrm{Hg}$ [35]. Hemorheologically, maintenance of $\geq 140 \mathrm{~mL}$ of stroke volume delivered by the left ventricle (LV) at regular rhythm of $\geq 40 /$ min and physiological pulse pressure (syst $B P \geq 80 \mathrm{~mm}$ $\mathrm{Hg}$ ) with a coronary perfusion pressure of $\geq 15 \mathrm{~mm} \mathrm{Hg}$ are required to ensure adequate organs perfusions and promote ROSC [36]. Hence it becomes an impossible task to achieve due to the hemostatic condition of cardiac arrest.

Anatomically, the heart is anchored in the body by the great vessels (Dr. Claude Beck) [37]. As is known, several centimeters separate the sternum from the free wall of the right ventricle (RV), followed by the interventricular septum and then the LV (Fig.1). Then the heart becomes further 
distant from the sternum, pushed backward by the mediastinum* ${ }^{*}$, once the cardiac arrest victim is placed on a supine position for chest compressions.

Likewise, insufficiencies of current CPR methods can be explained by the abovementioned pathophysiological barriers. For example, chest compressions either manually or mechanically must be strong enough to compress the bony sternum and then also the mobile soft mediastinal and cardiac structures, to deliver adequate stroke volume through the far distant nearly empty LV. As a result, the excessive compressive forces ( $\geq 8$ to $\left.16 \mathrm{bar} / \mathrm{in}^{2}\right)$ of mechanical CPR devices provoke most frequently cardiothoracic trauma, e.g., ribs fractures, cardiopulmonary contusion, mammary glands hematoma in females, ..., which contraindicate their use in pediatrics. Also, the high frequency of chest compressions ( $\geq 100 \mathrm{bpm}$ ) restricts recoil of the thorax as well as venous return during decompression and does not adapt the capillary pressure cycle (40 bpm) [38-40]. The benefits of AEDs are still debated, as a successful DC shock must be strong enough (e.g., $\geq 300$ joules) due to the deviation of the electric field with the anterolateral thoracic positions of the electrodes, resulting in approximately $4 \%$ of shock energy reaches the heart. Also, the prolonged depolarization period after strong shocks promotes myocardial necrosis and electroporation of the precious pacemaker cells that represent only about $1 \%$ of cardiomyocytes [41,42]. Skin burns $(\geq 25 \%)$, tachyarrhythmia, thromboembolic incidents, and pulmonary edema have been also reported after strong DC shocks [43]. Similarly, benefits of epinephrine during CPR remain controversial because of the hemostatic condition [44]. Also, the installation of ECMO via flattened empty arteries is extremely difficult in OHCA, limiting its applications to in-hospital environments $[45,46]$.

In this study, we were able to pattern the proposed therapeutic method through the clinical observations of Lifeguards for OHCA and Cardiac surgeons for induced IHCA, two categories that have been almost forgotten in the CPR literature. For example, in correlation with the Utstein style [47], lifeguards have the best results of OHCA with ROSC in about 70 to $90 \%$ of drowning victims (Fig.2) [48,49]. In addition to their rapid intervention, we believe that the Heimlich's maneuver (Fig.3A), which is constantly practiced by lifeguards for evacuating the aspired water, mobilizes massive amount of the hepato-splanchnic blood via the inferior vena cava which directly stimulates the conducting system with ROSC, even without CPR (Fig.3B). Likewise, the induced cardiac arrest has become a safe procedure, performed daily by cardiac surgeons with almost $100 \%$ return of heartbeat in patients with previous cardiomyopathy and underwent surgery for a significant length of time. Currently, with the advancement of cardiac reperfusion procedures, most of openheart surgery patients $(\geq 90 \%$ ) recover their heartbeat spontaneously without DC shock. It does not matter whether the heart is denervated or surgeons had to sacrifice the sinus node artery like occasionally with arterial switch procedures, the patient most often recovers a sinus rhythm.

\footnotetext{
* A well-known procedure performed by cardiac surgeons who switch-off ventilators during sternotomy to push the still beating heart away from the sternum.
} 
Perhaps one of the most impressive demonstration of ROSC in cardiac surgery is performed by Sir Magdy Yacoub* to wean his patients from CPB, by abrupt clamping of the venous lines that refills the RA instantly creating a snapping effect at the conducting system with immediate defibrillations of the heart.

The 3R/CPR: refill, recoil, rebound.

Therefore, in order to obtain an effective cardiac massage promoting rapid ROSC, we must overcome the abovementioned 3 obstacles: We need to overrule the sternal barrier and bring the heart closer to the chest wall. We need to refill the nearly empty heart. We need to recoil properly the chest wall. We need to induce a sudden rebound effect at the internal thoracic structures, including the intracardiac blood to create a snapping effect at the conducting system of the heart (e.g., likewise Sir Yacoub's method).

We have been assisted in this study by one of the most experienced Lifeguards' groups from Greece which has the highest drowning records in Europe [50].

\section{Steps:}

1. Positioning the SCA victim on a left recovery (lateral recumbent) position in order to bring the heart (apex) closer to the chest wall and secure his/her airway (Fig.3C\&D).

2. Raising the victim's lower body in a Trendelenburg-like position after gently, compressing and pushing upward the infradiaphragmatic (hepato-splanchnic) compartment, using any available materials e.g., pillows, sheets, lifeguards' materials... etc. Victims can be easily lifted from their waist belt (Fig.4A). Releasing any tight constrictive garments, e.g., belts, bras, ....

3. Placing the palm of the right hand at the $5^{\text {th }}$ intercostal space to feel if there is still heartbeat, for example under the breast by lifting and pushing it upwards in females (Fig.4B).

4. Adjusting the victim's position with the right hand and forearm pushing his/her chest backward and the right thigh pushing his/her flank forward (Fig.4C).

5. Induction of chest compressions: with both hands pushing the chest backward-upward at the $5^{\text {th }}$ intercostal space, while blocking the victim's back with both thighs and leaning forward on the victim's body to increase chest recoil in a nearly circumferential manner by apply additional compressions from the surrounding mediastinal structures.

6. Maintaining the compression with both hands for few seconds (Fig.4D).

7. Sudden releasing of both hands in a slight backward body (rescuer) motion (Fig.4E) to create an immediate rebound effect on internal structures, similar to the appendicitis tenderness test.

8. Preferably, the AED pads will be placed in an anteroposterior position (Fig.5).

9. Repeating the recoil-rebound maneuvers for 2 minutes, then try a DC shock (50-100J) with the victim in nearly supine position.

\footnotetext{
*Attending Sir Yacoub's operative sessions at the Royal Brompton and Harefield Hospitals (UK) in the early $90^{\text {th }}$.
} 
10. Return the victim to left recovery position for cardiac massage. To be repeated twice, within 3-4 intervals.

- With ROSC, the victim should be maintained in the left recovery Trendelenburg-like position with slight release of the abdominal compression, until arrival of professional rescuers to transfer him/her to hospitals for further postarrest management.

- Without ROSC, continue the 3R/CPR maneuver until arrival of professional rescuers for further management (e.g., mechanical ventilation) and transfer the victim to specialized cardiac centers.

N.B.

- The procedure should not be tried on alive individuals as it may provoke ventricular fibrillation (Commotio cordis syndrome). For example, we had to compress the abdomen, the lower intercostal spaces and water bags for the demonstration of the rebound maneuver.

- The technique is not suitable for neonates and infants, as long as we can recoil and compress the chest properly, e.g., in a circumferential manner (Fig. 6).

\section{Discussion}

Compared to current CPR, the proposed 3R/CPR technique can significantly improve outcome of SCA victims for several reasons. First, the restoration and maintenance of adequate perfusion of vital organs promoting ROSC can be achieved with rational mobilization of stagnant body fluids (e.g., blood, air), during cardiac arrest, instead of being shaken vigorously and inconceivably (CFR vs. CPR) [30]. For example, in the early onset of SCA, the 3R/CPR refill maneuver can shift a massive volume of the stagnant infradiaphragmatic venous capacitance to the cardiothoracic compartments to be handled properly with the recoil-rebound processes. However, an optimal chest recoil operation must be executed according to the rules of Biomechanics of the thoracic cage [51]. Therefore, we must take into account, the cylindrical shell-like thoracic cage, ribs' orientations and their movements on the axis of their attachments between 2 hard and fixed boney structures (sternum and spines) helped by the sternocostal, costochondral, costovertebral and costotransverse joints (Fig.1A), [52,53]. Accordingly, chest compressions through the $5^{\text {th }}$ intercostal space while leaning on the victim body in the left recovery position, can induce a nearly circumferential stress (hoop stress) on the cylindrical shell-like thoracic cage in respecting ribs' movements axis, which will be more effective and less traumatic for SCA victims and less exhaustive for rescuers. In addition, the left recovery position provides more safety for airway management and avoids iatrogenic mistakes by confusing cardiac arrest with similar clinical presentations. For example, a bystander who cannot distinguish between unconsciousness, cardiogenic shock, or cardiac arrest, can easily feel the heart apex beating his palm in the first two conditions (Fig.3D).

On the other hand, and contrarily to the rules of biomechanics, vigorous mid-sternal chest compressions induce deviated longitudinal stress causing the well-known complications of CPR 
[54-56]. It is important to remind that CPR was adopted at random in the early 1960 s, following the experiments of William Kouwenhoven, a pioneering engineer and inventor of the electrical defibrillator systems [57]. However, morphologically, the chosen animal model (adult dogs) is sorely different from humans. For example, in correlation to differences of the cardiotorsal anatomy with more obtuse sternocostal angle in dogs, chest compressions are usually performed laterally through the left thorax while the dog is placed on a right recumbent position rather than a supine position. In addition, dogs have a well-developed coronary collateral network that promotes ROSCs most often in canine models, contrarily to high mortality of porcine models [58].

Therefore, a proper execution of the refill-recoil-rebound processes can enhance chances of ROSC, directly by inducing a water hammer-like mechanism with a snapping effect at the internal pacemaker cells (ESS mechanism), and indirectly by improving the myocardial perfusion due to the increased RV preload. Besides, in our previous study with a low-pressure pulsatile suit device [59], we have shown that the RV subendocardial resistance vessels are more sensitive to mediators of vasodilatation and endothelium dependent dilators rather than increased transmural coronary flow [60-62].

As long as oxygen supply during CPR remains a debated procedure since mouth-to-mouth ventilation provides insufficient tidal volume for victims [63], it is best to continue the 3R/CPR without interruption until ROSC and / or arrival of professional rescuers for mechanical ventilation and transfer the victim to hospitals.

Likewise, due to controversies between chest compression first versus DC shock first remain unresolved, we prefer taking the first option for several reasons. First, we remind that a heartbeat starts by the action potential at the pacemaker cells of the conducting system of the heart and nothing else. Even DC shocks induce the same effect but indirectly through electroporation. So, it is fundamental to avoid unnecessary rupture of the very precious pacemaker cells, which constitute about $1 \%$ of cardiac myocytes. Secondly, we recall that in all circumstances of cardiac arrest there is a state of asystole, whether the heart is fibrillated or not (Fig.7A\&B), especially since the sensitivities of the electrocardiogram systems, even measured by 12 electrodes, remain questionable [64]. Third, the immediate ROSC with the first DC shock remains unclear, if not vague, in the literature. Therefore, we believe that cardiac tissue must be well perfused first before any trial of DC shock, for example, twice after 2 min of 3R/CPR with approximately 2-4 minutes intervals. The uncertainty of brain protection is another constate unresolved dilemma as well, causing significant neurological damage in most CPR survivors [65]. Alternatively, attempts to improve cerebral perfusion with intravenous hypertonic saline and/or nitrates remain controversial because of the hemostatic conditions [66-68].

As it is unwise to flog a tired horse (Fig.7C), we believe that early CAD is required in OHCA as it is done in heart surgery, even with short aortic cross-clamp time ( $\leq 20 \mathrm{~min})$, e.g., surgical correction of anomalous left coronary artery from the pulmonary artery (ALCAPA). This has been clearly 
demonstrated through the work of pioneering experts in myocardial protection [69]. In other words, the probabilities of reversible brain damage could be obtained once adequate perfusion was maintained as early as possible during cardiac arrest. As a symbolic example, represented in (Table 1) with our experience of four patients with ROSC after more than $30 \mathrm{~min}$ of cardiac arrest and had significant brain damages according to the intraoperative electroencephalogram (EEG) and/or postoperative CT scans reports. Three of them who had underwent open-chest direct cardiac massage and then $\mathrm{CPB}$, were fully recovered and discharged from the hospital. One patient who had subjected to closed chest cardiac massage (for $\geq 30 \mathrm{~min}$ ) before $\mathrm{CPB}$, showed permanent brain damage and expired shortly afterward. This may be supported with evidences of postmortem cellular viability and variant delay in organs biodegradation [70,71].

\section{Postarrest management}

The therapeutic goal in postarrest patients is to improve hemodynamics, tissue oxygenation and cellular metabolism to promote full recovery with restoring endothelial functions e.g., angiogenesis-apoptosis interdependency [72]. Maintaining good metabolic processes depend on organs' microcirculation which is controlled by plurality of endothelial mediators of vasodilators induced by ESS [73-75]. However, relying on vasopressors to improve hemodynamics may worsen endothelial dysfunction conditions by increasing vascular resistances and myocardial oxygen consumption, most likely end in organ failure and circulatory assist devices (CAD) requirement.

The association of moderate hypothermia with CPB and ECPR (ECMO), may improve tissue oxygenation and neurological damage in IHCA victims [44,76, 77]. However, ECMO (ECPR) which is widely recommended for SCA management and CPB remain invasive procedures, performed by specialized teamwork available in few cardiac centers. Besides, they provide a steady-flow perfusion mode that promotes to endothelial dysfunction complications with controversial results $[78,79]$. As is known, the encounter of CAD with the circulatory system creates vicious circle of endothelial dysfunction and momentum energy losses, manifested clinically with the postcardiotomy and post-hemodialysis syndromes [80,81], causing symptoms and signs like hemorrhage, thromboembolism, inflammatory response, apoptosis..., until multiple organ failure. This may be worsened by suppressing the important role of the respiratory pump as a master-key circulatory driving force and a potential generator of ESS. As ventilators with endotracheal intubation and neuromuscular blockades transform the respiratory pump into a pressurized, immobilized hydraulic circuit, along with their interference with coronary perfusion flow $[82,83]$.

Alternatively, unlike the steady flow of ECPR and conventional CPB, we have demonstrated the undeniable crucial role of endogenous endothelial mediators in controlling hemodynamics, microcirculation and metabolism with new generations of pulsatile CADs, regardless of cardiac conditions: healthy, dysfunctional [84], or even arrested [30]. In addition to the 3R/CPR that can improve results of chest compression, we believe that the rapid installation of the CFR device regardless to ROSC, can mobilize massive amount of stagnant blood volume ( $\geq 4$ liters) in a 
pulsatile noninvasive manner which can globally improve the outcome of SCA. In addition, the CFR device's vest, associated with a passive oxygen insufflation device serves as a noninvasive mechanical ventilator with a nasogastric tube could be useful during refractory cardiac arrest and in postarrest to prevent excessive ventilation in maintaining the pulmonary ESS $[85,86]$.

\section{Prophylaxis}

Trials of predicting and preventing incidents of pathophysiological SCA, are well defined and in constant progress in cardiology, e.g., Brugada syndrome [87]. However, we are more concerned about the high frequency of physiopathological OHCA during physical exercise. As most of these incidents occur due to a momentary disturbed impulses transmission through the conducting system of an absolutely healthy heart. A similar phenomenon is occasionally encountered in open-heart surgery as ventricular fibrillation may occur even without cardiomyopathy like in-vivo experiments, following hasty surgical manipulations. We intend to devote our next work to the prophylaxis of SCA in sports, especially since one of our patents (pulsatile combination) has been infringed and currently in use by sports elites, but in an unscientific manner that almost does worse than good.

\section{Limitations}

Unfortunately, the approval of the 3R/CPR concept cannot be achieved through animal models for morphological reasons or on clinical volunteers with the risk of Commotio Cordis. Therefore, we had to support our concept with rational and substantial scientific arguments based on clinical observations, fundamental medical and biomedical knowledges in organized common senses (Thomas Huxley).

\section{Perspectives}

We are planning to continue the development pathway of $3 \mathrm{R} / \mathrm{CPR}$, according to recent recommendations from the United States Food and Drug Administration [88]. We are planning preclinical 3R/CPR versus CPR comparative studies via computational models and/or cadavers $[89,90]$. According to the FINER criteria for a good research question and the phases of evaluation of new therapies, we believe that the $3 \mathrm{R} / \mathrm{CPR}$ technique is feasible, interesting, novel, ethical and relevant [91, 92].

\section{Conclusions}

Current CPR remains inappropriate and insufficient therapeutic concept for SCA victims, linked with serious complications and poor outcome. Alternatively, a 3R/CPR technique can overcome the three therapeutic barriers of CPR and adapt to thoracic biomechanics promoting potential improvement of SCA management. This represents a cost-effective method, suitable for all ages and genders. The technique should be combined as soon as possible with an adequate circulatory perfusion system, preferably noninvasive. 
Acknowledgments: We express our gratitude to Ms. Georgia Tsoungani, Mr. Nikitas Shmatov, Ms. Mani-Maria Bikof and Mr. Spiros Mavritsakis and the whole group of Hellas Lifeguards, Athens, Greece, for the realization of the present work.

Financial support: None.

Conflict of Interest: None. 


\section{References}

1. Huxley TH. Biogenesis and abiogenesis. Nature 1870;2:400-7.

2. Wukasch DC, Reul GJ, Milam JD, et al. The «stony heart» syndrome. Surgery 1972; 72 (6): P1071-1080. DOI:https://doi.org/10.5555/uri:pii:0039606072902103

3. William A, Gay Jr., Ebert PA. Functional, metabolic, and morphologic effects of potassium$\begin{array}{llllll}\text { induced } & \text { cardioplegia. } & \text { Surgery } & 1973 ; & 74 & \text { (2): }\end{array}$ 290.DOI: https://doi.org/10.5555/uri:pii:0039606073900627

4. Corrado D, Basso C, Thiene G. Sudden cardiac death in young people with apparently normal heart. Cardiovasc Res 2001;50:399-408.

5. Wick R, Gilbert JD, Byard RW. Cafe coronary syndrome fatal choking on food: an autopsy approach. J Clin Forensic Med 2006;13:135-8.

6. Link MS. Mechanically induced sudden death in chest wall impact (commotio cordis). Prog Biophys Mol Biol 2003;82: 175-86.

7. Thygesen K, Uretsky B F. Acute ischaemia as a trigger of sudden cardiac death, Eur Heart J 2004; 6 (Suppl.):D88-D90, https://doi.org/10.1016/j.ehjsup.2004.05.006

8. Marcus FI, McKenna WJ, Sherrill D, et al. Diagnosis of arrhythmogenic right ventricular cardiomyopathy/dysplasia: proposed modification of the task force criteria. Circulation 2010; 121:1533-41.

9. Engdahl J, Bång A, Karlson BW, et al. Characteristics and outcome among patients suffering from out of hospital cardiac arrest of non-cardiac aetiology. Resuscitation 2003;57:33-41. doi: 10.1016/s0300-9572(02)00433-1.

10. de la Grandmaison GL. Is there progress in the autopsy diagnosis of sudden unexpected death in adults? Forensic Sci Int 2006;156:138-44.

11. Deo R, Albert CM. Epidemiology and genetics of sudden cardiac death. Circulation 2012;125:620-37. doi: 10.1161/CIRCULATIONAHA.111.023838.

12. Fishman GI, Chugh SS, Dimarco JP, et al. Sudden cardiac death prediction and prevention report from a National Heart, Lung, and Blood Institute and Heart Rhythm Society workshop. Circulation 2010;122:2335-48.

13. Brooks SC, Bigham BL, Morrison LJ. Mechanical versus manual chest compressions for cardiac arrest. Cochrane Database Syst Rev 2011;CD007260.

14. Vaillancourt C, Stiell IG. Canadian Cardiovascular Outcomes Research Team (CCORT) cardiac arrest care and emergency medical services in Canada. Can J Cardiol 2004; 20:108190.

15. Svensson L, Bohm K, Castrèn M, et al. Compression-only CPR or standard CPR in out-ofhospital cardiac arrest. N Engl J Med 2010; 363:434-42.

16. Peura JL, Colvin-Adams M, Francis GS, et al. Recommendations for the use of mechanical circulatory support: device strategies and patient selection: a scientific statement from the American Heart Association. Circulation 2012;126: 2648-67. 
17. Trohman RG, Parrillo JE. Direct current cardioversion: Indications, techniques, and recent advances. Crit Care Med 2000; 28 (Suppl.):N170-3. doi: 10.1097/00003246-20001000100010.

18. Nolan JP, Soar J. Defibrillation in clinical practice. Curr Opin Crit Care 2009;15:209-15.

19. Coats AJ. MADIT II, the multi-center autonomic defibrillator implantation trial II stopped early for mortality reduction, has ICD therapy earned its evidence-based credentials? Int J Cardiol 2002;82:1-5.

20. Niemann JT, Cairns CB, Sharma J, Lewis RJ. Treatment of prolonged ventricular fibrillation. Immediate countershock versus high-dose epinephrine and CPR preceding countershock. Circulation 1992;85:281-7.

21. Plaisier BR. Thoracic lavage in accidental hypothermia with cardiac arrest--report of a case and review of the literature. Resuscitation 2005;66:99-104. doi: 10.1016/j.resuscitation.2004.12.024.

22. Lasa JJ, Rogers RS, Localio R, et al. Extracorporeal Cardiopulmonary Resuscitation (E-CPR) During Pediatric In-Hospital Cardiopulmonary Arrest Is Associated With Improved Survival to Discharge: A Report from the American Heart Association's Get With The GuidelinesResuscitation (GWTG-R) Registry. Circulation 2016; 133:165-76. doi: 10.1161/CIRCULATIONAHA.115.016082.

23. Kern KB, Morley PT, Babbs CF, et al. Use of adjunctive devices in cardiopulmonary resuscitation. Ann Emerg Med 2001; 37:68-77.

24. Peberdy MA, Callaway CW, Neumar RW, et al. Part 9: post-cardiac arrest care: 2010 American heart association guidelines for cardiopulmonary resuscitation and emergency cardiovascular care. Circulation 2010; 122:768-86.

25. Zed PJ, Abu-Laban RB, Shuster M, et al. Update on cardiopulmonary resuscitation and emergency cardiovascular care guidelines. Am J Health Syst Pharm 2008; 65:2337-46.

26. Oeser C. Cardiac resuscitation: continuous chest compressions do not improve outcomes. Nat Rev Cardiol 2016; 13:5.

27. Binks A, Nolan JP. Post-cardiac arrest syndrome. Minerva Anestesiol 2010; 76:362-8.

28. Rubertsson $\mathrm{S}$ et al. Mechanical chest compressions and simultaneous defibrillation vs conventional cardiopulmonary resuscitation in out-of-hospital cardiac arrest: the LINC randomized trial. JAMA 2014;311:53-61.

29. Perkins GD, Ji C, Deakin CD, et al. A Randomized Trial of Epinephrine in Out-of-Hospital Cardiac Arrest. N Engl J Med 2018; 379: 711-72. doi: 10.1056/NEJMoa1806842.

30. Nour S, Carbognani D, Chachques JC. Circulatory flow restoration versus cardiopulmonary resuscitation: new therapeutic approach in sudden cardiac arrest. Artif Organs 2017; 41: 356366.

31. Shanmugasundaram M, Lotun K. Refractory Out of Hospital Cardiac Arrest. Curr Cardiol Rev 2018;14:109-114.

32. Mery A, Almond F, M_enard C, et al. Initiation of embryonic cardiac pacemaker activity by inositol 1,4,5-trisphosphate-dependent calcium signaling. Mol Biol Cell 2005;16:2414-23. 
33. Hachida M, Saitou S, Nonoyama M, et al. Mechanisms of exercise response in the denervated heart after transplantation. Transplant Proc 1999;31:1966-9.

34. Schwerzmann M, Salehian O, Harris L, et al. Ventricular arrhythmias and sudden death in adults after a Mustard operation for transposition of the great arteries. Eur Heart $\mathrm{J}$ 2009;30:1873-9.

35. Anderson RM, The Gross Physiology of the Cardiovascular System. San Carlos PL, Tucson, AZ: Racquet Press 4625, 1999.

36. Reynolds JC, Salcido DD, Menegazzi JJ. Coronary perfusion pressure and return of spontaneous circulation after prolonged cardiac arrest. Prehosp Emerg Care 2010;14:78-84.

37. Beck, B. S. The developments of a new blood supply to the heart by operation. Ann Surg 1935; 102: 809-13.

38. Guidelines 2000 for cardiopulmonary resuscitation and emergency cardiovascular care. Part 6: advanced cardiovascular life support: section 4: devices to assist circulation. The American Heart Association in collaboration with the International Liaison Committee on Resuscitation. Circulation 2000;102:I105-11.

39. Deakin CD, Nolan JP, Soar J, et al. European resuscitation council guidelines for resuscitation 2010 Section 4. Adult advanced life support. Resuscitation 2010;81:1305-52.

40. Mangold S, Miller S, Aebert H. Rupture of the right ventricle after closed-chest cardiac massage. Circulation 2010;122:1657.

41. Lown B. The shock that cures: DC and cardioversion. In: Lown B, ed. The Lost Art of Healing. New York, NY: Houghton Mifflin Co., 1996;188-201.

42. Ohuchi K, Fukui Y, Sakuma I, et al. A dynamic action potential model analysis of shockinduced aftereffects in ventricular muscle by reversible breakdown of cell membrane. IEEE Trans Biomed Eng 2002;49:18-30.

43. Bardy GH, Lee KL, Mark DB, et al. Home use of automated external defibrillators for sudden cardiac arrest. N Engl J Med 2008;358:1793-804.

44. Jespersen HF, Granborg J, Hansen U, et al. Feasibility of intracardiac injection of drugs during cardiac arrest. Eur Heart J 1990;11:269-74.

45. Tajik M, Cardarelli MG. Extracorporeal membrane oxygenation after cardiac arrest in children: what do we know? Eur J Cardiothorac Surg 2008;33:409-17.

46. Polimenakos AC, Rizzo V, El-Zein CF, et al. Postcardiotomy rescue extracorporeal cardiopulmonary resuscitation in neonates with single ventricle after intractable cardiac arrest: attrition after hospital discharge and predictors of outcome. Pediatr Cardiol 2017;38:314-23.

47. Idris AH, Bierens JJLM, Perkins GD, et al. 2015 Revised Utstein-Style Recommended Guidelines for Uniform Reporting of Data From Drowning-Related Resuscitation: An ILCOR Advisory Statement. Circ Cardiovasc Qual Outcomes 2017;10:e000024. doi: 10.1161/HCQ.0000000000000024.

48. Youn CS, Choi SP, Yim HW, Park KN. Out-of-hospital cardiac arrest due to drowning: An Utstein Style report of 10 years of experience from St. Mary's Hospital. Resuscitation 2009;80:778-83. doi: 10.1016/j.resuscitation.2009.04.007. 
49. Venema AM, Groothoff JW, Bierens JJ. The role of bystanders during rescue and resuscitation of drowning victims. Resuscitation 2010; 81:434-9.doi: 10.1016/j.resuscitation.2010.01.005.

50. Franklin RC, Peden AE, Hamilton EB, et al. The burden of unintentional drowning: global, regional and national estimates of mortality from the Global Burden of Disease 2017 Study Injury Prevention 2020;26:i83-i95.

51. King A.I. Impact Biomechanics of the Thorax. In: The Biomechanics of Impact Injury. Springer, Cham. 2018. https://doi.org/10.1007/978-3-319-49792-1_11

52. Timoshenko S and Woinowsky-Krieger S. General theory of cylindrical shells. Chap- 15. Theory of Plates and Shells. $2^{\text {nd }}$ Ed. MaGraw-Hill Book Company, Inc. NY. 1987, Pp. 466.

53. Arbogast KB, Maltese MR, Nadkarni VM, et al. Anterior-posterior thoracic force-deflection characteristics measured during cardiopulmonary resuscitation: comparison to post-mortem human subject data. Stapp Car Crash J 2006;50:131-45. PMID: 17311162

54. Jang SJ, Cha YK, Kim JS, et al. Computed tomographic findings of chest injuries following cardiopulmonary resuscitation: More complications for prolonged chest compressions? Medicine (Baltimore) 2020;99: e21685. doi: 10.1097/MD.0000000000021685.

55. Yamaguchi R, Makino Y, Chiba F, et al. Frequency and influencing factors of cardiopulmonary resuscitation-related injuries during implementation of the American Heart Association 2010 Guidelines: a retrospective study based on autopsy and postmortem computed tomography. Int J Legal Med 2017;131:1655-1663. doi: 10.1007/s00414-017-1673-8.

56. Lardi C, Egger C, Larribau R, et al. Traumatic injuries after mechanical cardiopulmonary resuscitation (LUCAS2): a forensic autopsy study. Int J Legal Med 2015;129:1035-42. doi: 10.1007/s00414-015-1146-x.

57. Kouwenhoven WB, Jude JR, Knickerbocker GG. Closed chest cardiac massage. JAMA 1960;173:1064-7.

58. Botran M, Urbano J, Solana M et al. 56 Cardiopulmonary Resuscitation by Chest Compressions Versus Ventilation Plus Chest Compressions in a Pediatric Asphyxial Cardiac Arrest Animal Model. Pediatr Res 2010; 68:31. https://doi.org/10.1203/00006450-201011001-00056

59. Nour S, Dai G, Wang Q, et al. The forgotten driving forces in right heart failure (Part II): experimental study. Asian Cardiovasc Thorac Ann 2012;20:646-57.

60. Manohar M, Bisgard GE, Bullard V, et al. Myocardial perfusion and function during acute right ventricular systolic hypertension. Am J Physiol 1978; 235:628-36.

61. Duncker DJ, Bache RJ. Regulation of coronary blood flow during exercise. Physiol Rev 2008;88:1009-86. 54.

62. Pelc LR, Gross GJ, Warltier DC. Preferential increase in subendocardial perfusion produced by endothelium dependent vasodilators. Circulation 1987;76:191-200.

63. Stallinger A, Wenzel V, Oroszy S, et al. The effects of different mouth-to-mouth ventilation tidal volumes on gas exchange during simulated rescue breathing. Anesth Analg 2001;93:1265-9.

64. Gupta V, Mittal M, Mittal V. R-peak detection based chaos analysis of ECG signal. Analog Integr Circ Sig Process 2020; 102:479-490. https://doi.org/10.1007/s10470-019-01556-1.

65. Laver S, Farrow C, Turner D, Nolan J. Mode of death after admission to an intensive care unit following cardiac arrest. Intensive Care Med 2004;30:2126-8. 
66. Breil M, Gräsner JT, Schewe JC, et al. Randomised study of hypertonic saline infusion during resuscitation from outof- hospital cardiac arrest. Resuscitation 2012;83:347-52.

67. Dezfulian C, Shiva S, Alekseyenko A, et al. Nitrite therapy after cardiac arrest reduces reactive oxygen species generation, improves cardiac and neurological function, and enhances survival via reversible inhibition of mitochondrial complex I. Circulation 2009;120:897-905.

68. Olasveengen TM, Sunde K, Brunborg C, et al. Intravenous drug administration during outofhospital cardiac arrest: a randomized trial. JAMA 2009;302:2222-9.

69. Allen BS, Buckberg GD. Studies of isolated global brain ischaemia: I. Overview of irreversible brain injury and evolution of a new concept - redefining the time of brain death. Eur $\mathrm{J}$ Cardiothorac Surg 2012;41:1132-7. doi: 10.1093/ejcts/ezr315.

70. Darzynkiewicz Z, Juan G, Li X, et al. Cytometry in cell necrobiology: analysis of apoptosis and accidental cell death (necrosis). Cytometry. 1997; 27:1-20.

71. Fieux F, Losser MR, Bourgeois E, et al. Kidney retrieval after sudden out of hospital refractory cardiac arrest: a cohort of uncontrolled non heart beating donors. Crit Care 2009;13:R141.

72. Koh TJ, DiPietro LA. Inflammation and wound healing: the role of the macrophage. Expert Rev Mol Med 2011; 13: e23.

73. Samet I, Lelkes PI. Mechanical forces and endothelium. Harwood academic publishers, The Netherlands, 1999, 2-11.

74. Neri Serneri GG. Pathophysiological aspects of platelet aggregation in relation to blood flow rheology in microcirculation. Ric Clin Lab 1981; 11: 39-46.

75. Koller A, Kaley G. Endothelium regulates skeletal muscle microcirculation by a blood flow velocity-sensing mechanism. Am J Physiol 1990; 258: 916-20.

76. Bernard SA, Jones BM, Horne MK. Clinical trial of induced hypothermia in comatose survivors of out-of hospital cardiac arrest. Ann Emerg Med 1997;30:146-53.

77. Nagao K, Kikushima K, Watanabe K, et al. Early induction of hypothermia during cardiac arrest improves neurological outcomes in patients with out-of-hospital cardiac arrest who undergo emergency cardiopulmonary bypass and percutaneous coronary intervention. Circ J 2010;74:77-85.

78. Undar A, Wang S, Izer JM, Clark JB, et al. The clinical importance of pulsatile flow in extracorporeal life support: the Penn state health approach. Artif Organs 2016;40:1101-4.

79. Nour S, Liu J, Dai G, et al. Shear stress, energy losses and costs: a resolved dilemma of pulsatile cardiac assist devices. Biomed Res Int 2014;2014:651769.

80. Brettner F, Chappell D, Schwartz L, et al. Vascular Endothelial Dysfunction During Cardiac Surgery: On-Pump Versus Off-Pump Coronary Surgery. Eur Surg Res 2017; 58:354-368.

81. Davison SN. Pain in Hemodialysis Patients: Prevalence, Cause, Severity, and Management. Am J Kidney Dis 2003; 42:1239-47.

82. SOS-KANTO study group. Comparison of arterial blood gases of laryngeal mask airway and bag-valve-mask ventilation in out-of-hospital cardiac arrests. Circ J 2009;73:490-6.

83. Cooper JA, Cooper JD, Cooper JM. Cardiopulmonary resuscitation: history, current practice, and future direction. Circulation 2006;114:2839-49. 
84. Nour S. New hemodynamic theory "Flow and Rate": concept and clinical applications using new pulsatile circulatory assist devices. Ph.D. Thesis, Therapeutic Innovations, University Paris Sud, Paris XI; Français. 2012. NNT: 2012PA114862.

85. Bobrow BJ, Ewy GA, Clark L, et al. Passive oxygen insufflation is superior to bag-valve-mask ventilation for witnessed ventricular fibrillation out-of-hospital cardiac arrest. Ann Emerg Med 2009;54:656-62.

86. Nour S. Endothelial shear stress enhancements: a potential solution for critically ill Covid-19 patients. BioMed Eng OnLine 2020; 19:91. doi:10.1186/s12938-020-00835-7.

87. Brugada J, Brugada P. Right bundle branch block, persistent ST segment elevation and sudden cardiac death: a distinct clinical a distinct clinical and electrocardiographic syndrome. A multicenter report. J Am Coll Cardiol 1992;20:1391-6.

88. Guan A, Hamilton P, Wang Y, et al. Medical devices on chips. Nat Biomed Eng 2017; 1: 4510.

89. Clayton RH. Computational models of normal and abnormal action potential propagation in cardiac tissue: linking experimental and clinical cardiology. Physiol Meas 2001;22:R15-34. doi: $10.1088 / 0967-3334 / 22 / 3 / 201$.

90. Duhem H, Viglino D, Bellier A, et al. Cadaver models for cardiac arrest: A systematic review and perspectives. Resuscitation 2019;143:68-76. doi: 10.1016/j.resuscitation.2019.08.009.

91. Hulley SB, Cummings SR, Browner WS, et al. Designing clinical research. $4^{\text {th }}$ ed. Philadelphia: Lippincott Williams \& Wilkins; 2013.

92. Pocock S J, Clayton TC, Stone DW. Challenging issues in clinical trial design Part 4 of a 4part series on statistics for clinical trials. Jam Coll Cardiol 2015; 66: 2886-2898. 


\section{Table}

Tableau 1: Open CPR in patients subjected to $\geq 30$ min of cardiac arrest:

\begin{tabular}{c|ccccccccc}
\hline \multicolumn{2}{l}{$\begin{array}{l}\text { Age } \\
\text { (Sex) }\end{array}$} & Etiology & $\begin{array}{c}\text { CPR } \\
\text { (invasive) }\end{array}$ & $\begin{array}{c}\text { DC } \\
\text { shock }\end{array}$ & CPB & Scan & EEG & Drawbacks & Recovery \\
\hline 1 & $74 \mathrm{y}(\mathrm{F})$ & Rupture aortic arch & $\sqrt{ }$ & - & $\sqrt{ }$ & $\sqrt{ }$ & - & $\sqrt{ }$ & Full \\
2 & $3 \mathrm{~h} \mathrm{(M)}$ & Congenital aortic sten. & $\sqrt{ }$ & - & $\sqrt{ }$ & $\sqrt{ }$ & - & $\sqrt{ }$ & Full \\
3 & $31 \mathrm{y}(\mathrm{F})$ & Rupture LV & $\sqrt{ }$ & - & $\sqrt{ }$ & $\sqrt{ }$ & $\sqrt{ }$ & $\sqrt{ }$ & Full \\
4 & $30 \mathrm{y}(\mathrm{F})$ & Extracard.* & - & $\sqrt{ }$ & $\sqrt{ }$ & $\sqrt{ }$ & $\sqrt{ }$ & $\sqrt{ }$ & $\dagger$ \\
\hline
\end{tabular}

$\mathrm{F}=$ female; $\mathrm{M}=$ male; $\mathrm{y}=$ years; h: hours (newborn); Sten. = stenosis; $\mathrm{LV}=$ left ventricle; ${ }^{*}$ Extracard. = extracardiac cause of ventricular fibrillations during thoracoscopic surgery for a pneumothorax in young athletic doctor; $\mathrm{CPB}=$ cardiopulmonary bypass; $\mathrm{EEG}=$ electroencephalogram; Survival $=3$ deaths $=1=\mathrm{n} 1$ Electric Shock; $\sqrt{ }=$ yes; $-=$ none; $\boldsymbol{\dagger}=$ expired. 


\section{Figure legends}

Fig.1: Right panel (A): Midsternal chest CT scan showing the cardiotorsal anatomy of the shellshaped cylindrical thoracic cage of a living adult person. Left panel (B): colored schema of (A), showing distances between the heart and the thoracic cage (dashed color); Right atrioventricular cavity (blue color); Left atrioventricular cavity (red color); Pulmonary parenchyma (pink color); descending thoracic aorta (red color); Green arrows: simulated circumferential (Hoop) stress of 3R/CPR; Blue arrows: simulated deviated longitudinal stress of CPR chest compressions.

Fig.2: Lifeguard's drowning report (Ms. G. Tsoungani: 2002-2020), Paleo Faliro, Greece.

Fig. 3A: Demonstration of a rescue operation. The rescue Tube may serve as a tool for abdominal compression at the beginning of the Heimlich maneuver.

Fig. 3B: Simulation of CPR chest compression by the Lifeguard instructor. N.B. The lifeguard could not feel the beating heart of her colleague via the sternum.

Fig. 3C: Transfer to the left recovery position by the Lifeguard instructor.

Fig. 3D: Checking if the victim is still alive. N.B. The lifeguard felt very easily the strong heartbeat hitting her palm via the $5^{\text {th }}$ intercostal space.

Fig. 4A: Lifting the presumed SCA victim by the author. The victim can be lifted effortlessly by the waist.

Fig. 4B: Adjustment of the presumed SCA victim position with both hands and the right thigh in the direction of the green arrows.

Fig. 4C: Induction of a nearly circumferential chest compressions by leaning forward and compressing the victim body with both hands, forearms and thighs (green arrows).

Fig. 4D: Recoil maneuver by maintaining the chest compressions for several second.

Fig. 4E: Rebound maneuver by abrupt release of chest compressions.

Fig. 5: AEDs electrodes to be installed in the anterolateral position.

Fig. 6: Demonstration of chest compressions in neonates and infants.

Fig.7A: Hemodynamics data of induced extracardiac SCA in an asphyxiated pediatric dog. Left panel showing asystole state of a knocked-out myocardium. Right panel showing restorations of hemodynamics with a CFR device after 30 min of arrest [30].

Fig.7B: Hemodynamics data of induced cardiac SCA in piglet with $10 \mathrm{~mL} \mathrm{KCl}$ (IV). Left panel showing asystole state with myocardial fibrillations. Right panel showing restorations of hemodynamics with a CFR device after 20 min of arrest [86]. ECG: upper red line; Aortic pressure: middle green line; Carotid doppler flow: lower blue line.

Fig. 7C: Hemodynamics data of induced cardiac SCA in piglet with $10 \mathrm{~mL} \mathrm{KCl} \mathrm{(IV).} \mathrm{Left} \mathrm{panel}$ showing baseline. Middle panel showing asystole state of a knocked-out myocardium. Right panel showing ROSC with the CFR device after $15 \mathrm{~min}$ of arrest. N.B. A flogged myocardium state that that required mechanical assistance. ECG: upper red line; CVP: middle blue line; Aortic pressure: lower green line. 
Fig. 1

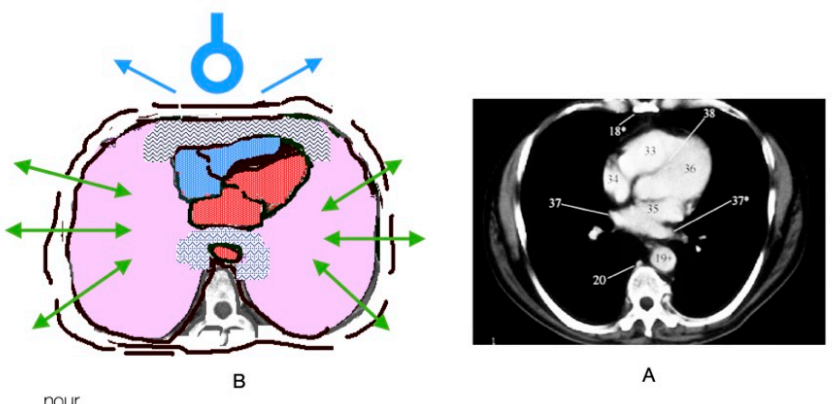


Fig. 2

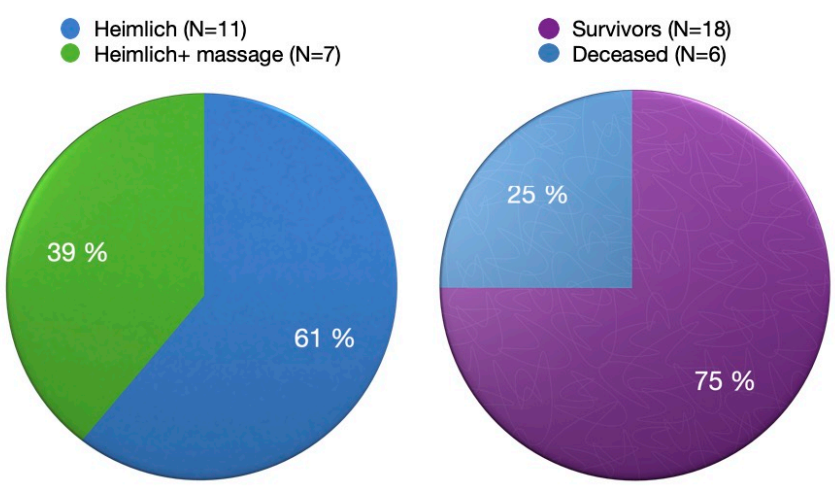


Fig. 3A

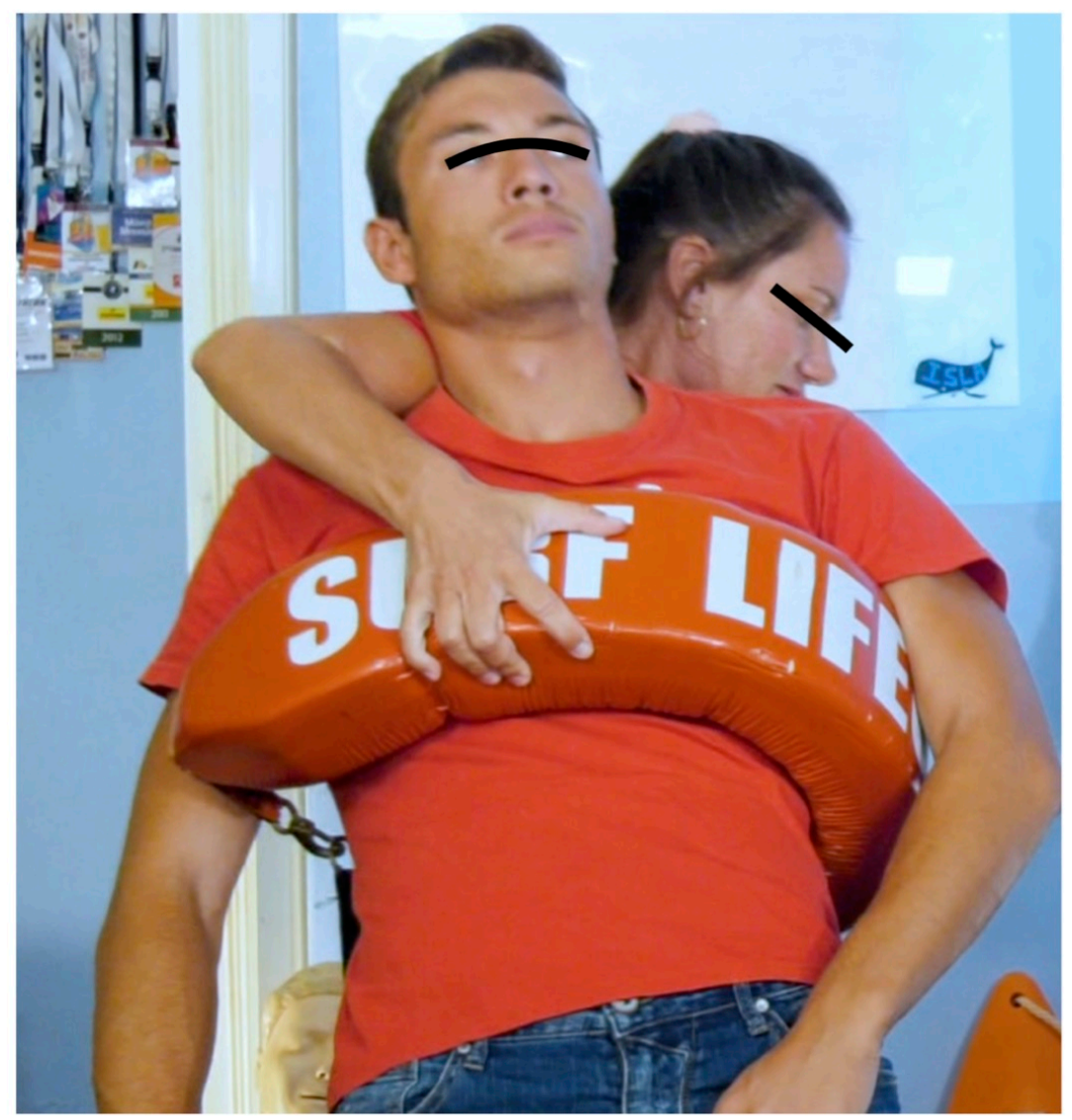


Fig. 3B

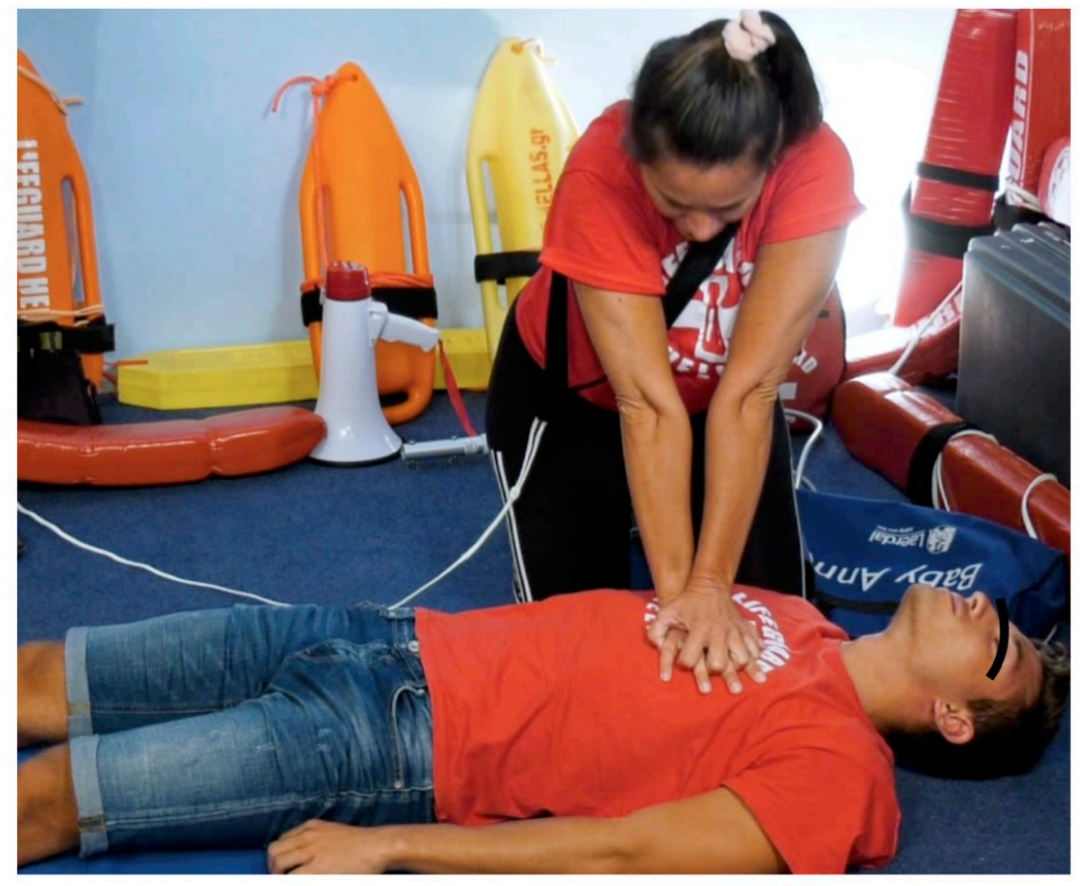


Fig. 3C

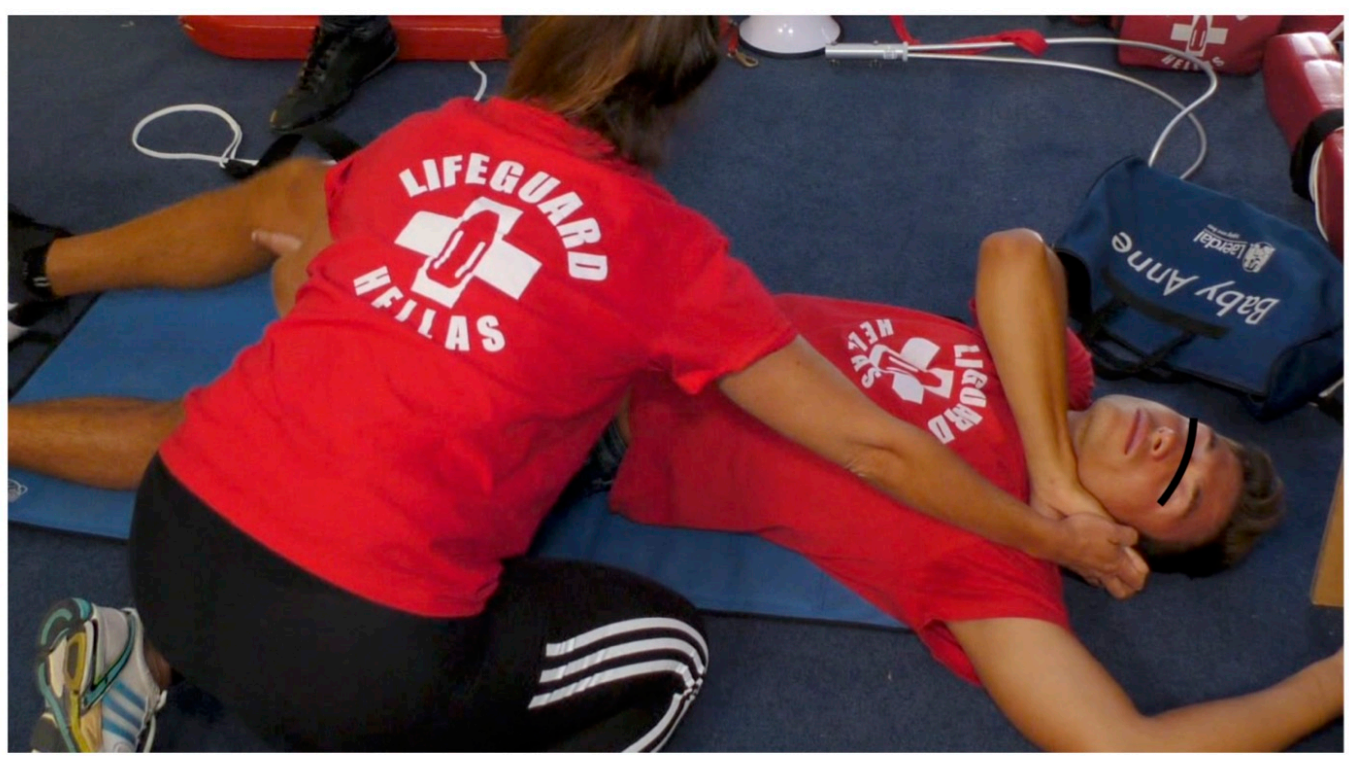


Fig. 3D

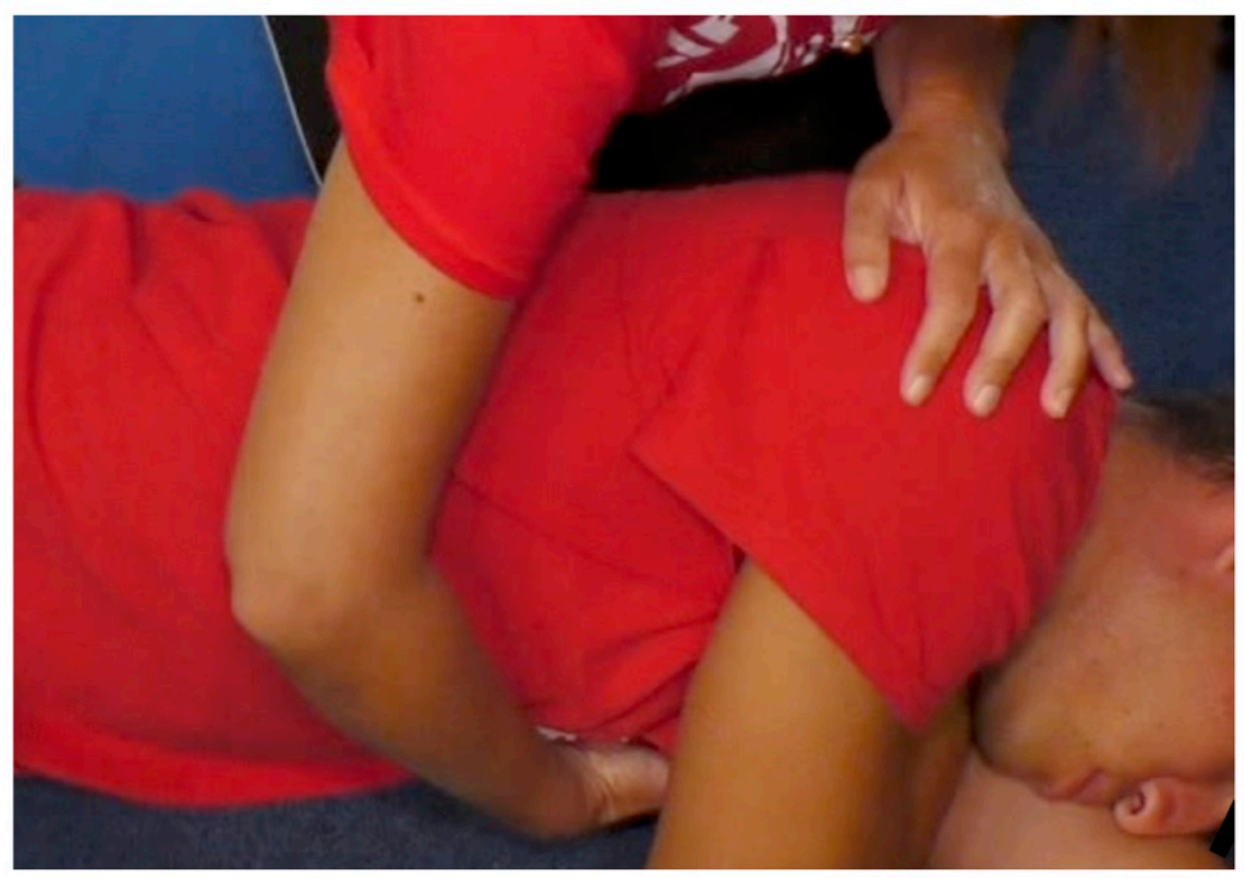


Fig. 4A

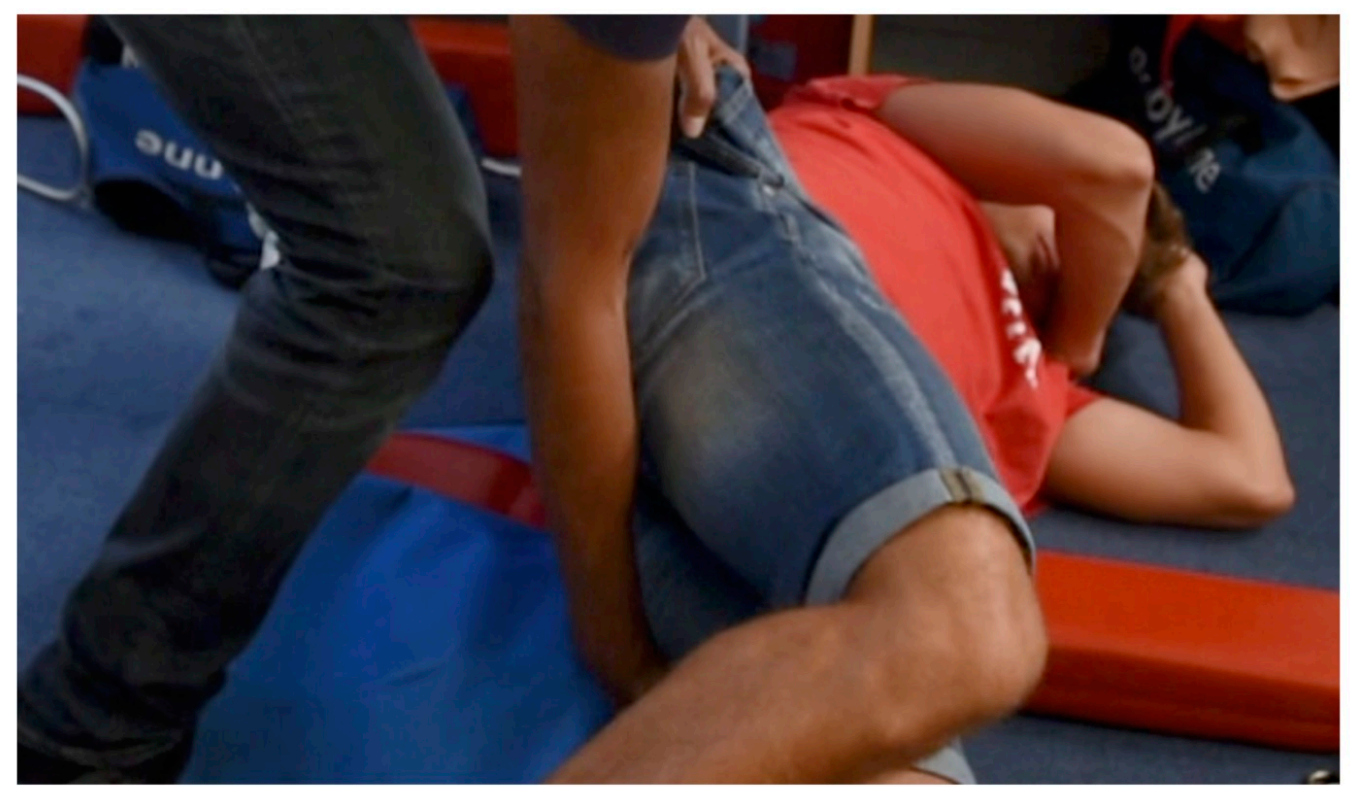


Fig. 4B

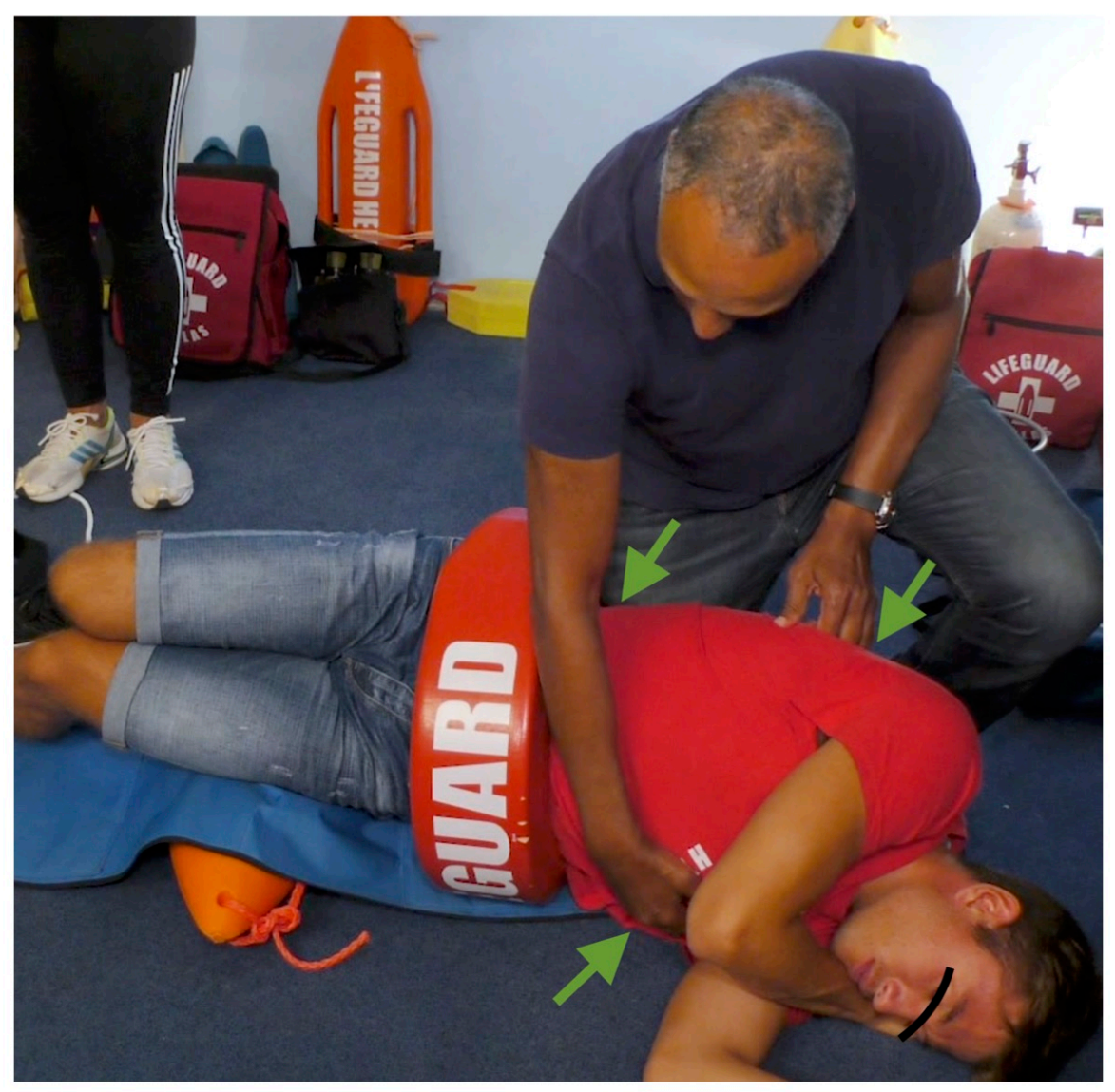


Fig. 4C

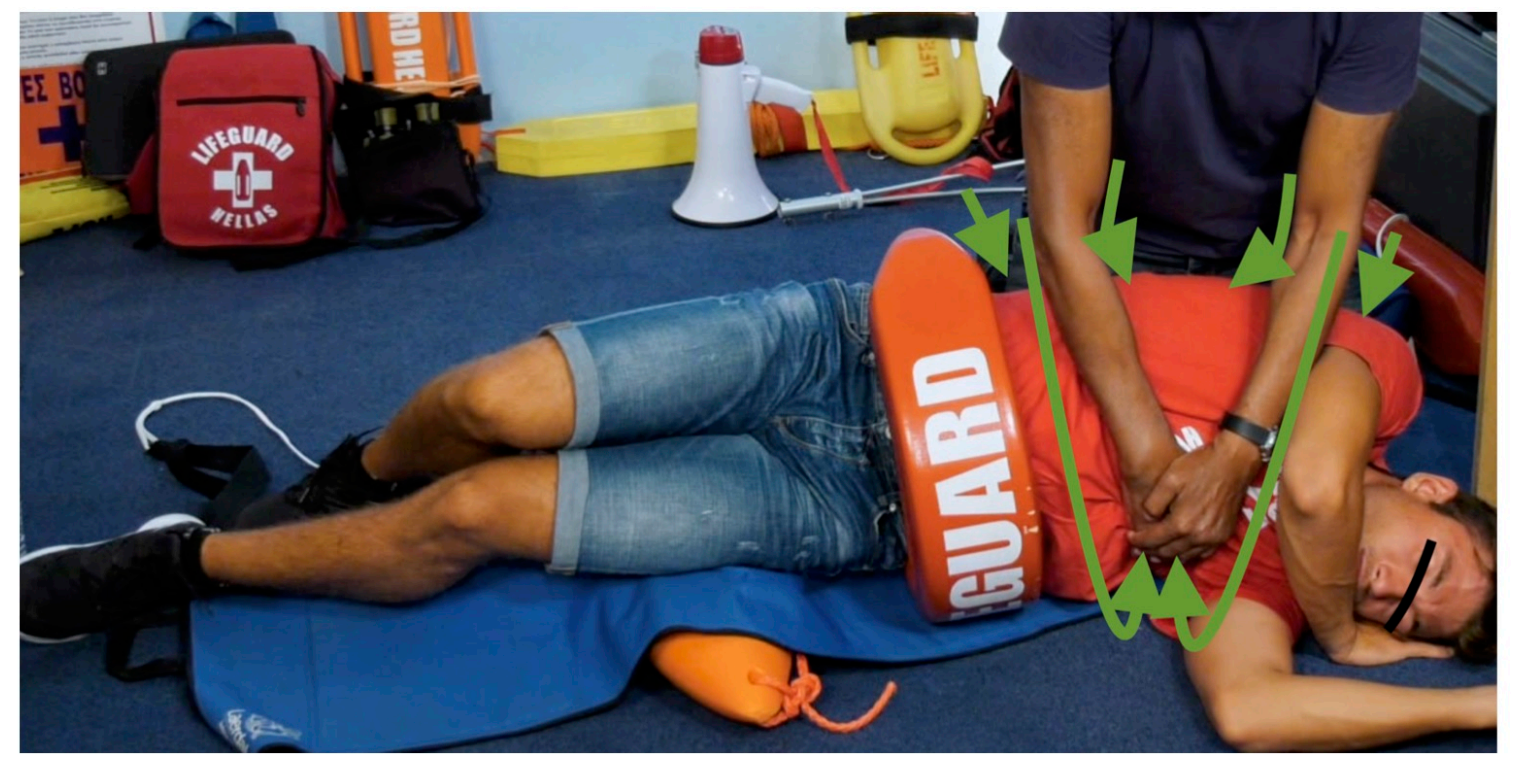


Fig. 4D

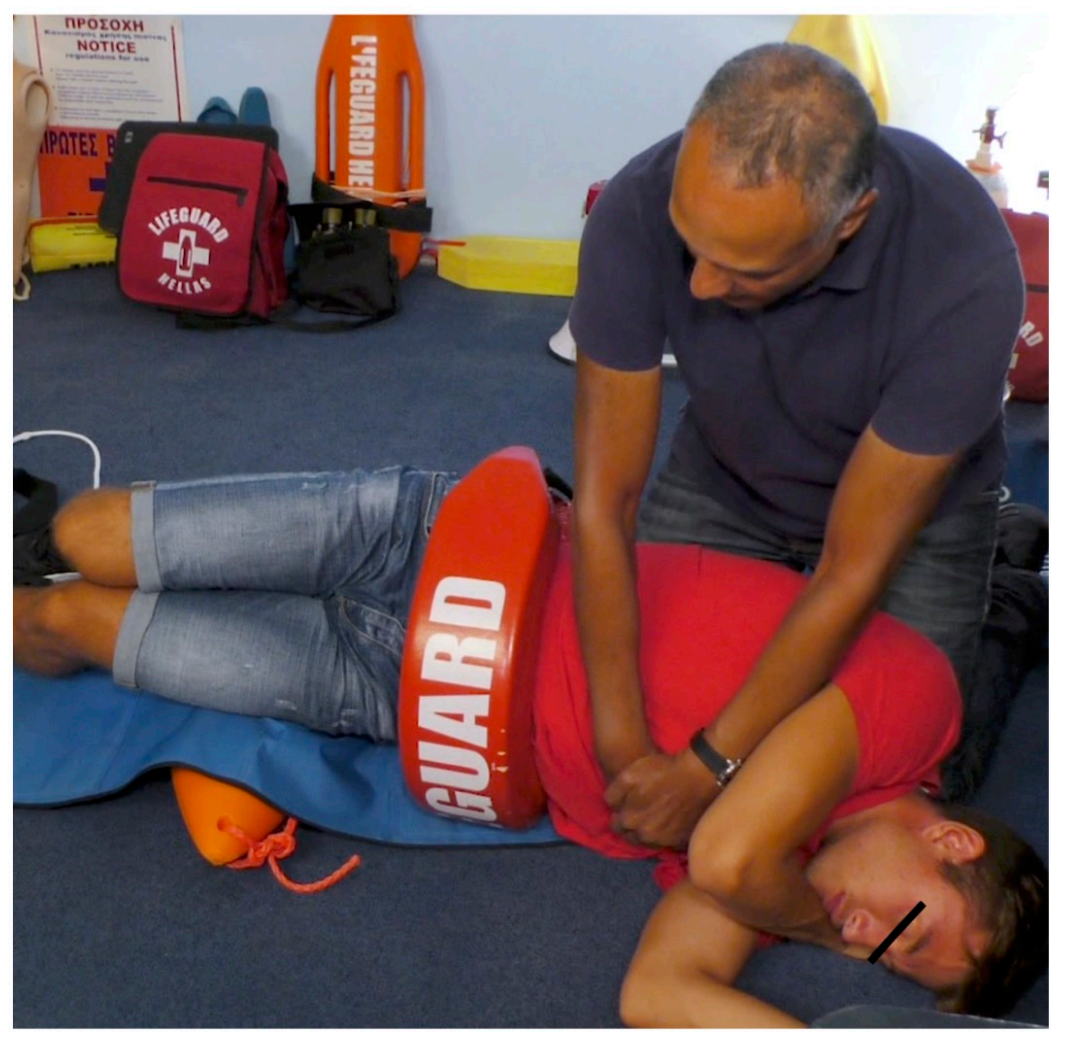


Fig. 4E

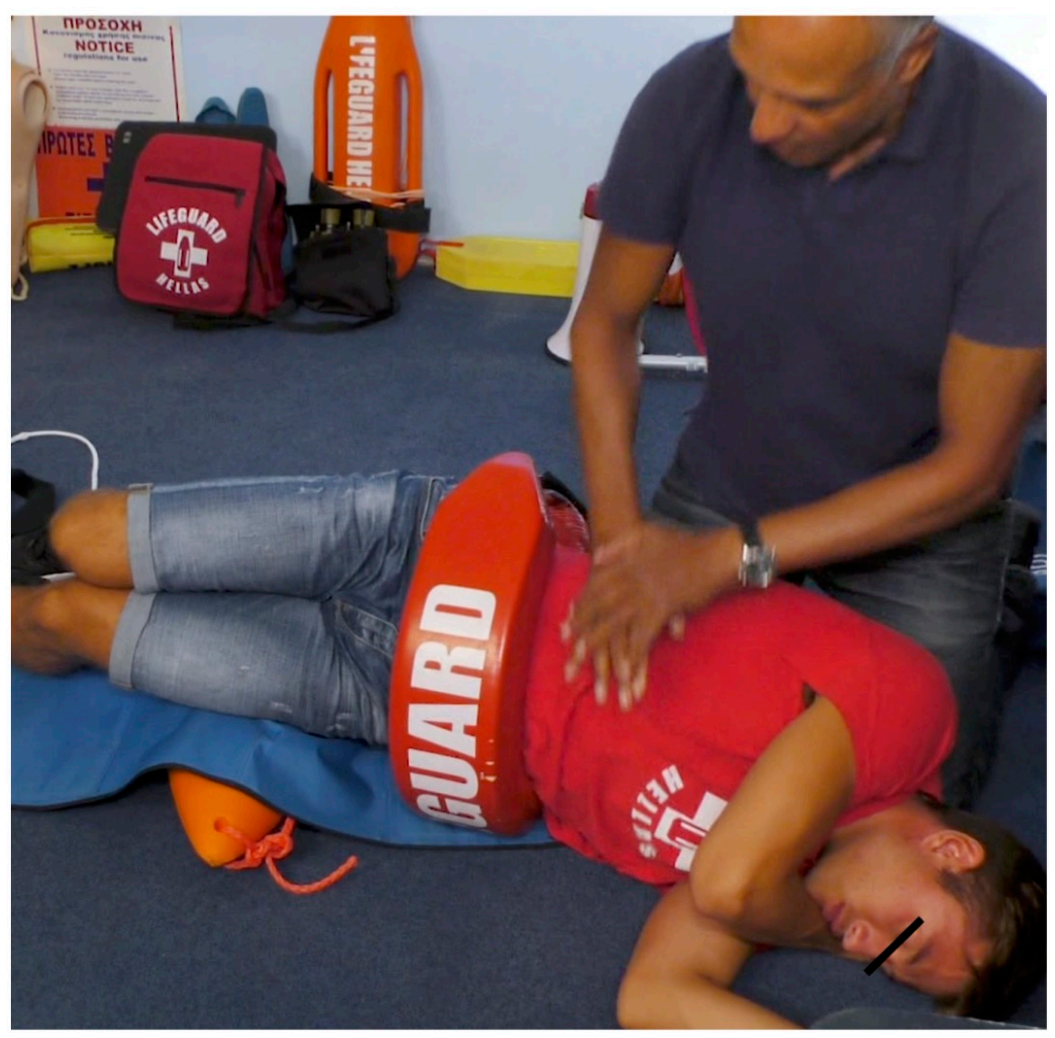


Fig. 5

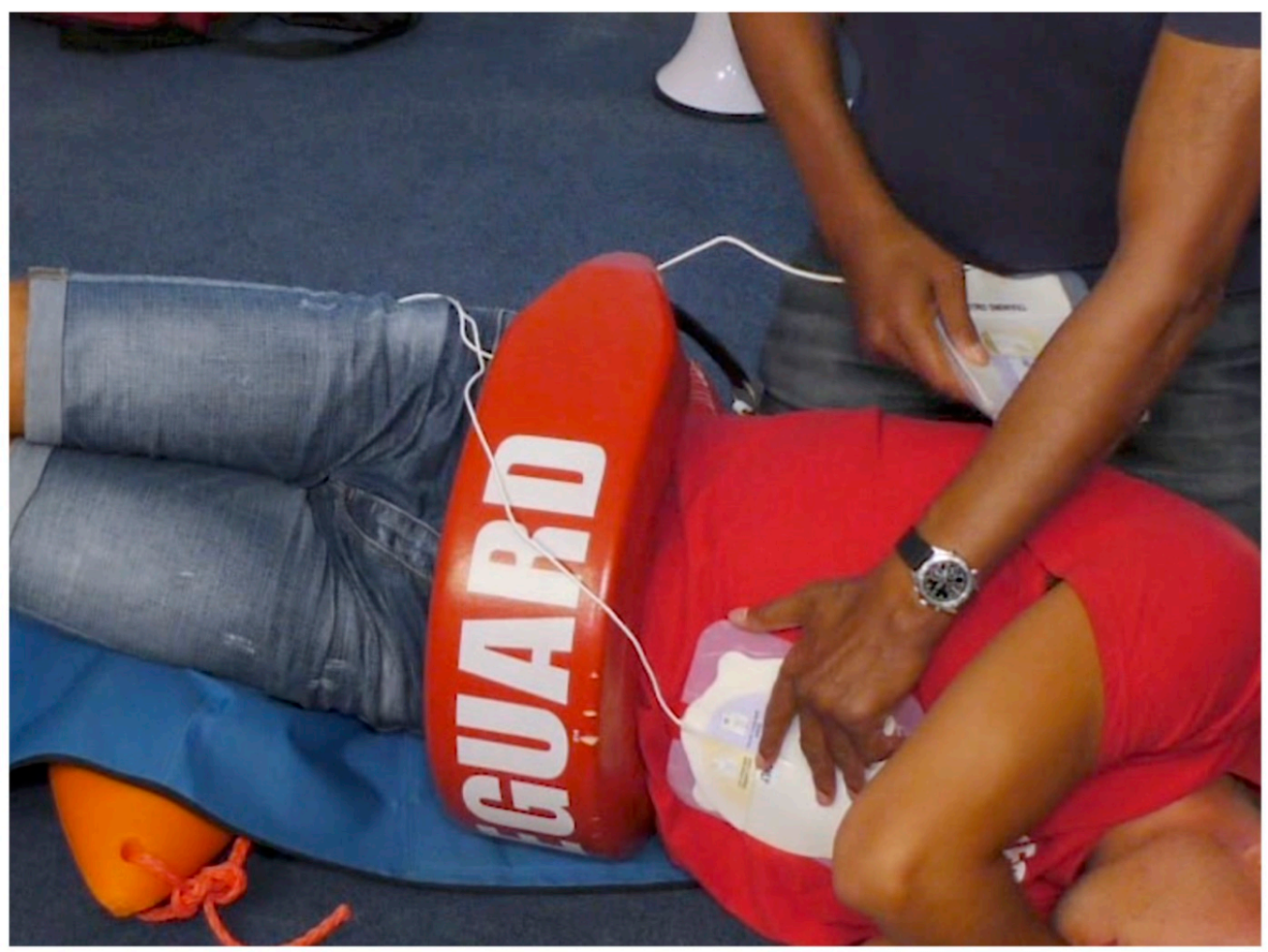


Fig. 6
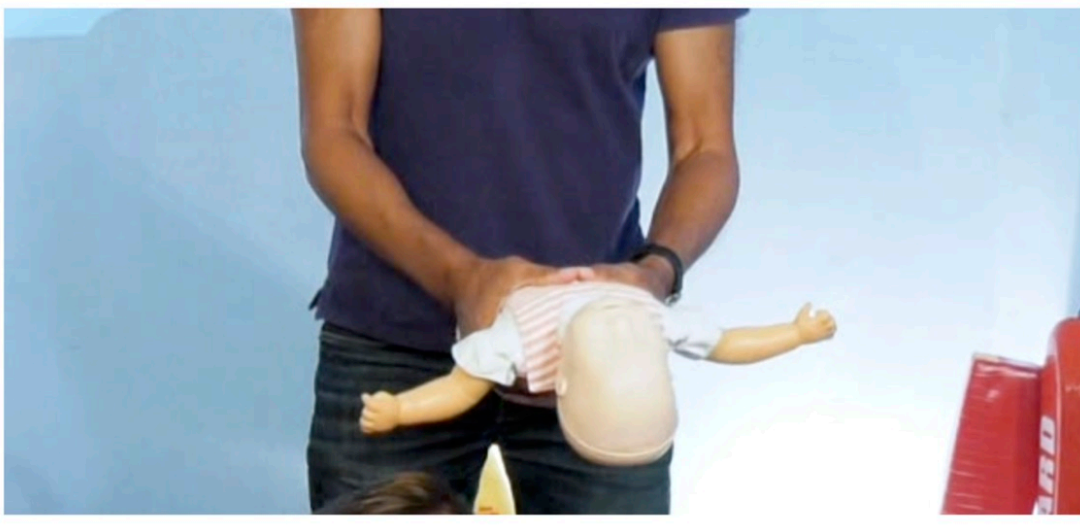
Fig. 7A

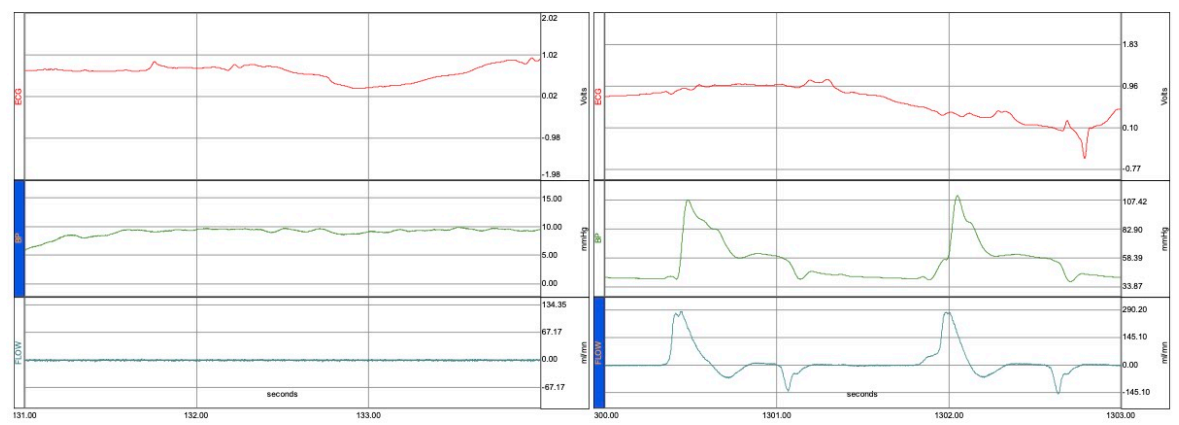


Fig. 7B

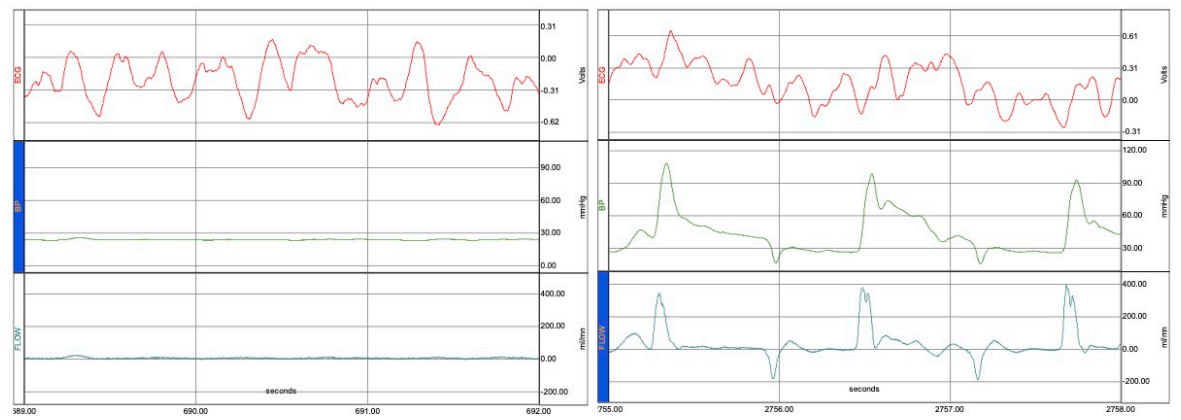


Fig. 7C

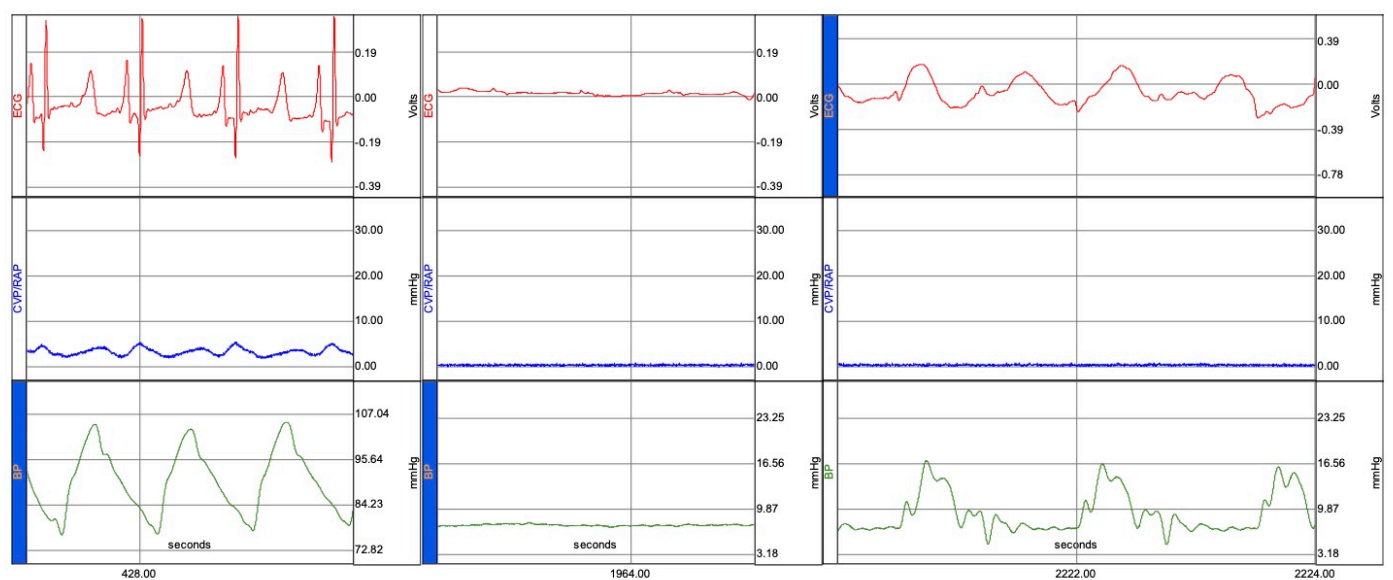

